I Universidade de São Paulo (USP),

Departamento de Antropologia, São Paulo, SP, Brasil

vagnergo@usp.br

https://orcid.org/0000-0002-I253-568I

Vagner Gonçalves da Silva'

\title{
LEGBA NO BRASIL - TRANSFORMAÇÕES E CONTINUIDADES DE UMA DIVINDADE
}

\section{EXU LEGBA DEMÔNIO - VISÕES CRUZADAS}

Exu, Elegbara e Legba são, entre os povos iorubas e fon-ewe situados na África Ocidental, divindades mensageiras, dinâmicas, temidas e respeitadas, que devem ser saudadas em primeiro lugar para não atrair confusão ou vingança. São deuses tricksters que questionam, invertem ou quebram regras e comportamentos. São associados aos processos de fertilidade e, sob a forma de um falo ereto, cultuados em altares públicos localizados na frente das casas, nos mercados e nas encruzilhadas. Quando seu culto foi "descoberto" pelos europeus iniciouse um processo no qual essas divindades foram associadas ao imaginário do mal, da desordem e da repressão sexual (ao demônio cristão e muçulmano) e, posteriormente ao mundo pré-moderno (primitivo), ao imaginário das forças antagônicas da modernidade, entre as quais estava, sobretudo, o pensamento mágico presente nas religiões que não passaram pelo processo da secularização ou burocratização.

A associação entre o falus no altar de Exu-Legba e o das iconografias do diabo pode ser revelador desse processo. Os ritos pagãos, assim vistos e condenados pela Igreja católica na Europa e entre os povos catequizados fora dela, incluíam as cerimônias de fertilidade nas quais era comum o uso de emblemas associados aos órgãos sexuais masculinos e femininos. A acusação do uso de báculos com ervas alucinógenas esfregados na boca ou na vagina levou muitas mulheres a ser acusadas de feitiçaria ou de cópula com o demônio. Por inson- 
dáveis caminhos do imaginário, a representação de um falo (posteriormente associado à vassoura) que as mulheres (acusadas de ser bruxas ou feiticeiras) usavam entre as pernas para saltar ou supostamente "voar" pelos campos propiciando-lhes a fertilidade, encontrou sua correspondência no falo de Exu que também era usado, segundo a mitologia ioruba, para que ele se transportasse ("voasse") para vários lugares instantaneamente. A condenação católica das divindades greco-romanas ou de outras origens associadas à sexualidade e fertilidade, consideradas "falsos deuses" ou demônios disfarçados, foi reeditada na África com a descoberta desse "Príapo negro", cultuado com danças tidas como obscenas e repletas de gestos "extravagantes e diabólicos" (Verger, I999: I35). O explorador inglês Alfred Burdon Ellis (I890: 4I) em finais do século XIX assim descreve essa associação:

Legba, Elegba or Lekpa é uma divindade fálica cujo culto se espalha por toda a Costa dos Escravos. O falo pode ser visto em todo lugar, em frente às casas, nas ruas e nos espaços públicos, às vezes sozinho, porém, frequentemente, em conexão com a imagem de Legba, cujo órgão é sagrado e seu principal atributo é a excitação sexual [...] A imagem de Legba é feita de barro vermelho e representa grosseiramente uma figura humana, em geral masculina, raramente feminina, e com frequência nua por inteiro. É sempre representado de cócoras e olhando seu órgão sexual, que é extremamente desproporcional. [...] Quando feminina, a figura é provida com seios longos e pontudos, e outros acessórios necessários [...] Bodes e galos são oferendas consideradas mais aceitáveis para Legba, por conta de suas disposições amorosas, e, também, os cachorros [...] Sonhos eróticos [...] são atribuídos a Legba, que se supõe possuir o corpo da pessoa durante o sono. Nisso talvez tenhamos uma chave para as crenças em tais demônios noturnos atuando como íncubos e súcubos e que perturbavam a paz das mentes de monges e freiras na Idade Média.

Ellis (2007: 65) acrescenta em outra obra uma descrição dos ritos que envolviam o falo de Elegba:

A rude representação de madeira do falo é fincada na terra do lado da cabana e é visto em quase todos os espaços públicos; por ocasião de certos festivais ele é ornamentado e levado em cortejo com grande pompa e apontado na direção das jovens mulheres que dançam ao redor dele.

O caráter erótico e o sacrifício de bodes, cães e porcos a Exu foram vistos como mais uma "evidência" de seu caráter demoníaco. Esses animais estavam associados na Europa ao diabo, que era pintado nas gravuras como um ser antropomórfico (com chifres, rabo e patas de porco ou bode) ou um "cão negro". Ou seja, Exu "comia" (recebia em sacrifício) na África o sangue dos animais que "davam corpo" ao diabo na Europa. Um dos resultados desse círculo "vicioso" foi o uso do termo "Exu" como tradução da palavra "Demônio", na versão ioruba da Bíblia, e "Iblis" e "Shaitan", na versão ioruba do Alcorão (Dopamu, I990: 20). Segundo a tradição islâmica, Iblis é uma criatura feita de fogo e o principal espírito maligno (Shaitan), o que "justificaria" sua aproximação com Exu, tido 
em um dos seus epítetos iorubas como o "Senhor do Fogo" (Exu Ina). Também na língua portuguesa setecentista essa "tradução" ocorreu. Na "Obra Nova de Língua Geral de Mina”, de Antonio da Costa Peixoto (I943-I944: 32), publicada em I74I e escrita a partir da língua ewe falada pelos escravos no Brasil, o termo "Leba" é traduzido por "Demônio". E essa tradução se mantém até hoje, até na própria África. No Dicionário Yoruba-Inglês (editado pela University Press Limited, Ibadan, Nigéria), o termo "elesù" (que se refere à pessoa que cultua ou foi consagrada a Exu) está traduzido para o inglês como "adorador do demônio", "possuída pelo demônio", “diabólico”, "mau”. A versão desse dicionário para o português seguiu a mesma tradução inglesa do termo.

A questão do pecado, do mal, ou da necessidade de um adversário do bem, entretanto, é algo que diz respeito muito mais às religiões monoteístas. Onde há muitas divindades (politeísmo) não se pode ter um antagonista que se oponha a um "Deus" único, já que esse não existe (Link, I998: I97). Daí a crítica ao emprego de termos como "demônio", "pecado", "mal" etc. para culturas em que esses conceitos não existem.

Esse processo de trocas estendido para as Américas ganhou novos interlocutores e complexidade ainda maior. Se, por um lado, o trabalho da conversão obrigatória propiciara a demonização, por outro lado, certas características de Exu-Legba possibilitaram uma absorção do catolicismo segundo os princípios cosmológicos da mitologia africana de origem. Isso porque, ao contrário do que ocorre no protestantismo, a presença no catolicismo português e espanhol de agentes mediadores entre os homens e Deus, como anjos, santos e mártires, facilitou a compreensão de Exu-Legba em seu aspecto de mensageiro.

Nesse sentido, Exu-Legbaa também foi associado aos santos cristãos e exaltado como mensageiro benfazejo. Em Cuba, ele foi relacionado ao maior mediador do catolicismo, Jesus Cristo, ou, mais precisamente, ao Menino Jesus de Atocha (Cabrera, 2004: I32). Afinal, segundo a teologia cristã, Jesus é ambiguamente humano e divino, o mensageiro por excelência de Deus enviado ao mundo para salvar os homens. "Ninguém chega ao Pai senão por mim", proclamou Jesus, segundo os evangelhos (João, I4:6). Vale lembrar que em Cuba há uma tendência para diferenciar Exu de Eleguá ou Leguá. O primeiro seria uma versão mais associada ao perigo e ao mal, e o segundo seria a versão benfazeja da entidade.

No Brasil, há menção a Exu ou Legba em documento do século XVIII, identificando-o ao demônio, como vimos. Na imprensa escrita da segunda metade do século XIX, essas referências aparecem, sobretudo, nas notícias de perseguição da polícia aos frequentadores dos templos religiosos afro-brasileiros, como no jornal Alabama, de Salvador, Bahia. Em jornais dos anos I 930 esses frequentadores eram chamados pejorativamente de fiéis de Exu (Fernandes, I937: I4), o que demonstra a visão negativa que envolvia a entidade e quem lhe prestava homenagens. O lado benfazejo de Exu associado aos santos católicos, 
porém, também se verificou no Brasil, ainda que com menor intensidade em comparação a Cuba. Ele foi associado a são Bartolomeu (santo católico relacionado igualmente a Oxumarê, orixá representado pelo arco-íris e que leva a água da terra para o céu), a santo Antônio, são Gabriel (anjo anunciador que traz as boas novas do céu aos homens), são Benedito (santo negro que deve sair em primeiro lugar nas procissões, para que não chova) e são Pedro (porteiro dos céus) (Bastide, I978: I8I; Valente, I955: I 26).

Em suma, Exu-Legba, quando abre os caminhos dos homens, compartilha com os santos católicos as qualidades tidas como "do bem". Mas quando lhes fecha os caminhos, ele é "do mal" e é comparado com as legiões de demônios que impedem o acesso dos homens aos bens do céu. Se, no entanto, Exu-Legba pode relativizar os conceitos do bem e do mal, sendo anjo ou demônio, o próprio diabo, que fora um anjo caído, pôde voltar a ser uma entidade do bem por meio das religiões afro-brasileiras. Por isso, o Exu-Demônio (uso o hífen como sinal dessa leitura) nunca representa o mal absoluto. Ou seja, por meio da linguagem dos demônios, santos e anjos católicos expandem-se as versões africanas de Exu-Legba como o propulsor ou bloqueador dos caminhos, mostrando que essa demonização não é fruto apenas da agência católica colonial. Exu-Legba não "é" o diabo e o diabo não "é" Exu-Legba, mas ambos podem estabelecer relações que ampliam seus significados a partir do contato entre os sistemas culturais que os originaram.

Exu-Legba no Brasil também se tornou um mediador entre as diversas denominações religiosas afro-brasileiras e o "grau de demonização" de seu culto passou a ser um indício do "grau de pureza" aferido pelos adeptos e pesquisadores em seus embates por legitimidade no campo religioso e acadêmico. Desde os primeiros relatos de Nina Rodrigues e Arthur Ramos, vê-se que quanto mais uma denominação religiosa aproxima Exu do Demônio, mais é considerada sincrética, "deturpada" e distante das heranças africanas tidas como "puras" ou legítimas. Nessa interpretação, os terreiros bantos (angolas, congos) e, sobretudo, a umbanda, pelo fato de ser considerados mais suscetíveis à influência do catolicismo e do espiritismo kardecista, teriam sido os grandes responsáveis pela "decadência" de Exu-Legba, em contraste com os terreiros de tradição jeje-nagô, nos quais essas entidades teriam sido preservadas em seu aspecto "mais africano". Vejamos especificamente o caso de Legba nos terreiros de tradição jeje no Brasil. 


\section{LEGBA ENTRE OS JEJE}

O vodum Legba, entre os Fon-ewe da África ou nos terreiros jejes no Brasil, possui atributos semelhantes aos de Exu na tradição ioruba. Segundo Maupoil (20I7: IOI):

Legbá é o vodum de todos os alimentos, de todas as colheitas, pois é ele quem rege todas as "contorções" do mundo, e tudo o que existe na natureza está sujeito a certas contorções antes de reproduzir-se. Se não se diz claramente que é Legbá quem faz tudo nascer e tudo crescer nesta vida, é precisamente para evitar mencionar essas mímicas inconvenientes

Tudo que nasce, cresce e reproduz (homens e colheitas) tem, portanto, relação com Legba, considerado um agente do movimento da vida. Cada ser humano possui um Legba que o acompanha desde o nascimento até a morte. Entre os Fon acredita-se que a pessoa é composta por vários elementos ou dimensões como o corpo físico, almas, espírito ancestral protetor, destino, vodum dono de sua cabeça e um princípio dinâmico que é Legba (Maupoil, 20I7: 393; Parés, 2016: 429).

Da mesma forma, cada vodum também tem seu Legba, que atua como uma espécie de braço direito, executor e protetor oficial. "Legba é o migan [primeiro-ministro ou comandante das Forças Armadas] de todos os voduns, seu justiceiro, sua cólera" (Maupoil, 2017: 97).

Legba está intimamente associado ao sacrifício por meio do qual o destino pode ser transformado. Esse aspecto estaria implícito na etimologia de seu nome e da reverência que desfruta como o "Grande Vodum":

Os fons explicam que Legbá, sempre em movimento, gira em torno do universo, fazendo rir e chorar o mundo inteiro. Seu nome evocaria essa particularidade: lé ('girar'), gba ('tudo'). Pensa-se mais comumente que Legbá significa "aquele que pega (o sacrifício)". O nome honorífico de hun-daho ('grande vodum') algumas vezes é dado a Legbá (Maupoil, 2017: I00).

Legba é cultuado sob vários nomes. Bernard Maupoil (2017: I02) descreve alguns deles e suas funções e significados.

Agbonuhósu (Rei do Portal) - Legba individual feito de terra, protetor da entrada da casa.

Légba do-Kó - Substituto do anterior protegendo a entrada da casa e assinalando que seu cultuador passou pelos ritos de Fá (Ifá em ioruba) na floresta. Possui um falo.

Legbá de Fá, Légba Agbãnukwen ou Agban-Nukon - Guardião e agente de ligação de Ifá e seus cultuadores. Em geral, esse Legba faz par com o anterior, porém é assentado na parte interna da casa, no quarto daqueles que se submeteram aos ritos de Ifá. A ele são dirigidos os sacrifícios iniciais associados à divindade da adivinhação. É feito de terra de cupinzeiro moldada em forma de uma efígie de argila que representa um homem sentado com destaque para 
seus dois falos (um de madeira e outro de ferro). É enfeitado com colares de búzios, penas e agulha sobre a cabeça.

Ahi-Légba - Senhor dos Mercados.

To-Légba - Protetor local de uma comunidade (aldeia, região ou grupo familiar). É invocado por aqueles que não têm Legba individual.

Zangbeto-Légba - Protetor dos Zamgbetos, que são seres espirituais (guardiões noturnos) mantenedores da ordem na comunidade. É representado com chifres.

Hun-Légba - Defensor da entrada do templo do vodum.

Tchuakésan (em ioruba) - Protetor do jogo divinatório feito com búzios.

Legbá Mawuton - Legba de Mavu. Preside o jogo de búzios nas consultas feitas pelos adivinhos de Legba. É representado por uma estatueta antropomorfa de madeira vestida com traje de miçangas coloridas. Recebe um pouco do sangue de todo sacrifício prescrito pela adivinhação.

Legbá Jobióna (Legba que está na frente da porta e come obi) - Associado a alguns odus (signos) de Ifá. É representado por dois Legbas, de costas um para o outro, o que lhe permite ver Mavu e Lisa ao mesmo tempo. Protege a casa contra maus espíritos. Geralmente é assentado na casa dos grandes adivinhos e recebe obis dos visitantes.

Legbá Aovi - Legbá com quatro cabeças associado a um signo de Ifá muito negativo que evoca desgraças (aovi). Faz-se oferenda de sacrifício a ele abandonando numa encruzilhada uma estatueta de argila com quatro cabeças.

No Brasil, o vodum Legba é cultuado na maioria das casas da nação jeje e suas variantes regionais. ${ }^{2}$ Há referências a seu culto em importantes casas de Salvador, como no Bogun (Zoogodô Bogum Malê Rundô), e da região do Recôncavo, como na Roça do Ventura (Zogbodo Male Bogum Seja Hundés) em Cachoeira. Nesse caso, Legba divide com outras entidades a função de abertura dos rituais.

Nos terreiros jeje-mahis de Cachoeira observa-se que, apesar de possíveis inversões de ordem, o ciclo de festas anuais se inicia com as obrigações para Aizan, Ogum Xoroque e Legba, divindades características e exclusivas da nação jeje. Nenhuma dessas entidades "raspa ninguém" e, portanto, não se manifestam em corpo humano. Aizan está ligado aos ancestrais da comunidade, e Ogun Xoroque e Legba são os mensageiros que abrem o caminho para os demais voduns, por isso são homenageados em primeiro lugar. Esses três voduns também atuam como os guardiões do terreiro [...] Atualmente, nos terreiros jejes são conhecidos e cultuados, além de Legba, uma pluralidade de "qualidades" referidas como Exus, o que indica uma progressiva penetração dos referentes nagôs em relação a essa figura. De modo ilustrativo podem ser citados: Lalu (assentado na porta do barracão do Bogum), Tiriri (assentado na entrada do Seja Hundê), Birigui, Agbo que "toma conta das folhas", Obará, "dono do dinheiro", Mirim, "dos Ibeji", e Vereketu (talvez uma evolução fonética de Averekete), que acompanha Legba e Ogum Xoroquê (Parés, 2006: 335). 
Práticas similares existem nos terreiros jeje do Sudeste, muitos dos quais mantêm laços de filiação com os terreiros baianos, como na Casa de Culto Dambala Kuere-Rho Bessein, ${ }^{4}$ localizada em Santo André, região metropolitana de São Paulo. Nessa casa a estrutura dos assentamentos situados na entrada (Xorokue, ou Ogum Xoroque, Ayzan e Legba) segue a estrutura dos terreiros jeje-mahin de Cachoeira nos quais essas três divindades são sempre homenageadas em primeiro lugar. Além disso, devido à introdução nessa casa de práticas jeje do Haiti, há na casa o culto ao Barão Samedi, um loa (espírito) associado à morte e à sexualidade, geralmente debochado, amante das bebidas e representado pela cruz e símbolos fálicos.

Uma particularidade significativa no culto afro-brasileiro a Legba ocorre no tambor de mina do Maranhão e áreas vizinhas, o que atesta continuidades e rupturas históricas entre as comunidades jeje das duas costas do Atlântico. O tambor de mina é constituído por duas tradições, a mina-jeje e a mina-nagô, representadas por dois terreiros tidos como "casas-mãe", a Casa das Minas e a Casa de Nagô, respectivamente, ambas localizadas em São Luís. ${ }^{5}$

$\mathrm{Na}$ Casa das Minas, onde somente voduns são cultuados, Legba não possui assentamento e não desempenha o papel de mensageiro dos voduns, função atribuída aos toquens, voduns jovens ${ }^{6}$ (Ferretti, I986: I 26). Com base em possíveis evidências de fontes históricas e relatos de tradição oral, Pierre Verger (I990) sugeriu que a Casa das Minas teria sido fundada por membros da família da rainha Na Agontimé, deportada ao Brasil como escrava pelo rei Adandozan, seu enteado, devido à disputa interna de poder na família real daomeana ocorrida em finais do século XVIII. Entre as evidências, Verger considerou o culto a voduns reais, a começar por Zamadonu, presente no nome africano da Casa das Minas (Querebentan de Zomadonu ou Casa de Zamadonu). Esses voduns são conhecidos exclusivamente em Abomé (Benim) e cultuados pelos reis que antecederam Adandazon (I797-I8I8). Acontece que Adandozan tinha Legba como seu "grande deus",7 o que possivelmente explicaria o apagamento de seu culto pela família fundadora da Casa de Zomadonu. Segundo Sergio Ferretti (I986: I22), que pesquisou a Casa durante décadas: "as filhas dizem que Legba significa guerra e confusão e que Zomadonu não quis ele lá pois as fundadoras já vieram da África sacrificadas".

O culto a Legba, de fato, parece ter sido particularmente importante para os reis daomeanos:

Cada rei tinha o seu Legba, com sua casa ou templo, geralmente com um legbasi, ou sacerdote de Legba, assistido por vários dependentes. No tempo de Tegbesu [1740-1775], o legbasi devia se suicidar após a morte do rei (Parés, 2013: 355).

A importância político-religiosa de Legba e a associação desse vodum com os inimigos das possíveis fundadoras da Casa das Minas talvez expliquem por que, mesmo sem dedicar culto organizado à divindade, essas fundadoras 
temiam sua ação e precaviam-se de sua fúria com algumas deferências rituais discretas.

Conseguimos saber que costuma-se colocar água para ele [Legba] na porta da casa, cedo, antes do início das cerimônias. É o despacho, que é feito com água do comé ou peji. Assim ele bebe água, mas fora da casa e não recebe oferenda de alimentos. Soubemos também que nos dias de festas, antes de se iniciarem os toques, canta-se na varanda um cântico para Legba se afastar (Ferretti, I986: I23).

Vale lembrar que na tradição jeje em geral não existe propriamente um rito semelhante ao padê nagô. Entre os Jeje da Bahia e de outros estados, Legba, Aizan $^{8}$ e Ogum Xoroque compõem a tríade de voduns mensageiros cujas obrigações precedem as dos demais voduns. No espaço físico, seus assentamentos ocupam a entrada da casa marcando seus atributos de divindades fronteiriças e guardiãs. Segundo Parés (2006: 337), ainda que a funcionalidade de abertura das obrigações dessas três entidades lembre certos aspectos do padê, não se trata da mesma coisa.

O gesto de derramar água no chão é também repetido no ritual jeje durante o zandró, 9 quando se canta para Legba e Ogum Xoroque, e a homenagem aos ancestrais fundadores do terreiro corresponde, no jeje, à obrigação de Aizan. Portanto, embora existam ressonâncias do padê na liturgia jeje, ou vice-versa, tanto a identidade das divindades mediadoras como as práticas rituais a elas associadas são diferentes, de modo que a ausência do padê, como apontam os praticantes jejes, constitui um dos traços distintivos da liturgia jeje.

$\mathrm{Na}$ Casa de Nagô em São Luís, cujo panteão abrange os voduns jeje, os orixás nagôs e outras entidades conhecidas como caboclas e gentis, Legba também não possui assentamento sendo lembrado apenas com uma cantiga na abertura dos toques, sem oferenda alimentar, para que não perturbe as cerimônias (Ferretti, 2009: 4).

Outro nome que Legba possivelmente teria assumido, ainda nas regiões Norte e Nordeste do Brasil, entre os praticantes do tambor da mata ou terecô, ${ }^{\text {Io }}$ sobretudo na cidade maranhense de Codó, foi Légua Boji (e suas variantes: Légua Boji Buá e Légua Boji Buá da Trindade).

A origem desse nome de acordo com a linguista Yeda Castro (2004: I 28) seria:

Legba/Légua, gênio do espaço celeste (gboji) imensurável (gla), por ser o dono dos caminhos dos céus e da terra, ou seja, entre os voduns e entre esses e os humanos, o que justifica a crença de que ele, ao mesmo tempo, possui as chaves dos céus e, na terra, é o dono superior das encruzilhadas (Fon: tobotoboji). ${ }^{\text {II }}$

Segundo Mundicarmo Ferretti (I993: I 25), esse vodum "entrou na mata e, como os caboclos brasileiros, gosta de cachimbo, de bebida alcoólica e da brincadeira". 
Légua Boji comanda a principal e mais temida família de "entidades da mata" tida como perigosa por executar trabalhos poderosos, seja para o "bem", seja para o "mal" (nesse caso, chamados de feitiços, macumbas ou "magia negra"). Atribui-se a Légua Boji e sua família participação na fama que a cidade de Codó adquiriu como "terra da magia".

Légua Bogi e os encantados de sua família, além de beberem muito (característica estranha aos voduns da Mina), são violentos e conhecidos como "malvados" - quando contrariados podem jogar seus "cavalos" na lama ou no chão, fazê-los subir em árvore de que depois não podem descer sozinhos, entrar em mata de espinho, e há quem diga que são capazes de tirar-lhes a vida [...]. Não raramente ouve-se falar, tanto em São Luis como em Codó, que Légua Bogi "tem uma banda branca e outra preta" ("uma de Deus e outra do Diabo"). Devido a essas características os encantados da família de Légua têm sido considerados semelhantes a Légua e próximos aos Exus da Quimbanda. E por causa delas há muito quem afirme que Légua Bogi é Legba disfarçado [...] e, no passado, muitos terreiros antigos procuravam afastá-lo logo que entrava no barracão [...]. E, se Codó é conhecida nos terreiros de Mina como "terra do Terecô" ou de Légua Bogi, é denominada por muitos maranhenses como "terra da macumba" [...], foi chamada pelo padre codoense Benedito Everton de "terra do feitiço" [...] e, em 1994, foi apresentada em programa da TV Bandeirantes como a "capital da magia negra”. Contra essa última visão, foi publicado em São Luís, no jornal O Imparcial, de I7/9/I994, um repúdio de entidades negras reunidas no "I EMCB" intitulada: "A imagem distorcida - entidades repudiam desinformação sobre religião afro-maranhense". Mas, depois do programa da BAND, Codó tem sido mais visitada por pesquisadores e adeptos da religião afro-brasileira e entrou na rota do "turismo religioso" internacional (Ferretti, I999: 43).

Deve-se observar, contudo, que os praticantes do terecô em Codó tendem a não associar o encantado Légua Boji ao vodum Legba. O culto a esse vodum é praticamente inexistente no terecô, bem como é inexpressivo no tambor de mina. Assim, apesar do caráter perigoso e trapaceiro de Légua Boji, ele não é classificado como da "linha negra". Esta linha em geral está associada à quimbanda e/ou umbanda na qual Exus e Pombagiras são cultuados (Ferretti, I999: 44; Centriny, 20I5: 227).

Para tornar o quadro ainda mais complexo, Légua Boji também pode se manifestar como um nobre e velho sábio de cabelos grisalhos, e, nesse caso, é tido como um "vodum cambinda" (banto). Segundo a hipótese de Yeda Castro (2004: I 27),

Talvez, nesse momento, possa ser encontrada uma explicação para o fato de Légua Boji, embora reencarnando o vodum Legba, haver assumido, segundo a crença popular, uma identidade nobre, na condição de caboclo, como ser da mata, e cambinda, de origem congo-angola, por não mais ser mina. Assim, recebeu o título em português de "barão", por decalque ao termo ewe-fon Baranõ, mestre Bara, isto é, senhor (nõ) do encantamento e mistérios (bara), como se passa no culto vodu do Haiti, onde se manifesta como Barão de Samedi, Barão do Cemitério, Barão de Lacruá. [...] No Maranhão, é lembrado no apelido do líder religioso afro-brasileiro Bita do Barão, justificando a fama de que goza por seus trabalhos na "linha-da-mata" e na "linha-negra". 


\begin{abstract}
Seja como for, a possível origem fon do nome de Leguá Boji e alguns dos seus atributos (fumo, bebida, jocosidade) parecem aproximá-lo do aspecto trickster e ordenador/desordenador característico do vodum africano Légba ("traduzido" ocidentalmente em termos de bem/mal, branco/preto, Deus/Diabo). E com a atual e crescente migração do candomblé nagô e da umbanda provenientes de outros estados do Nordeste e do Sudeste, têm aumentado a presença de Exu e suas formas de culto nos moldes dessas denominações religiosas ocasionando novos diálogos e arranjos no já complexo panteão do tambor de mina e da encantaria maranhense.
\end{abstract}

\title{
CONCLUSÃO
}

A complexidade e diversidade do culto de Exu-Legba é fruto de um longo processo de contato iniciado na África Ocidental há séculos entre as religiões de origem fon-ioruba, banto e o cristianismo. Esse contato se expandiu para as Américas formando uma rede transatlântica que envolve atualmente inúmeras tradições de culto praticadas em países como Nigéria, República do Benim, Angola, Moçambique, Brasil, Cuba, Haiti e Estados Unidos.

Exu-Legba, como ser das encruzilhadas, das trocas, do movimento, associado ao falo e à fertilidade, é central para pensar essa rede transatlântica na medida em que nele os caminhos das tradições, da memória e das experiências se cruzam. Como personagem da desordem, por um lado, ele nos remete à própria perda dos elos da vida social dos africanos e seus descendentes ocasionada pelo regime escravocrata (desterritorialização, desumanização, sevícia, violência etc.). Por outro lado, como agente da ordem ele possibilita a rearticulação do mundo pela inversão, cooptação, resistência, jocosidade, criatividade, sedução, enfim, pelos atributos relacionados em geral aos seres que habitam às margens do mundo social ou sobrenatural.

Recebido em I9/I/20I9 | Revisto em I 2/5/20I9 | Aprovado em 20/5/2019 
Vagner Gonçalves da Silva é antropólogo e professor da Universidade de São Paulo, onde obteve o título de bacharel em ciências sociais e os de mestre e doutor em antropologia. Pósdoutor pela Harvard University onde foi fellow no W.E.B. Du Bois Institute for African and African American Research. Pós-doutor pela City University of New York (Graduate Center) onde também foi professor visitante como bolsista do Fulbright Scholar Program. Desenvolve pesquisas na área das populações afro-brasileiras, enfocando temas como religiosidade (candomblé, umbanda, neopentecostalismo, intolerância religiosa), relações entre religião e cultura brasileira (festas populares, música, capoeira, literatura, cinema etc.) e artes afro-brasileiras. Publicou e editou, entre outras obras, Candomblé e umbanda; Orixás da metrópole; O antropólogo e sua magia; Intolerância religiosa; Memória afro-brasileira (Coleção em 3 volumes) e Exu - Guardião da Casa do Futuro. 


\section{NOTAS}

I Este texto com modificações faz parte da edição revista e ampliada de minha tese de livre-docência, intitulada Exu Brasil - o senhor de muitos nomes, apresentada na Universidade de São Paulo, em 2013. Agradeço a Sergio Ferretti e a Mundicarmo da Rocha Ferretti que o leram e contribuíram com sugestões e aperfeiçoamentos. Agradeço ainda à Universidade de São Paulo, à Fundação de Amparo à Pesquisa do Estado de São Paulo (Fapesp) e ao Conselho Nacional de Desenvolvimento Científico e Tecnológico (CNPq) pelo apoio institucional e material à pesquisa da qual este texto é resultado. Minha última correspondência com Sergio Ferretti, falecido em maio de 20I8, tratou do tema deste artigo; aproveito para dedicar este trabalho a sua memória e enaltecer sua grande contribuição ao conhecimento da tradição jeje no Brasil.

2 Nos candomblés de nação jeje há ênfase nas contribuições religiosas provenientes da "área dos gbes falantes" que abrange etnias situadas no atual Benim, Togo e Nigéria, tais como os Adja, Gen, Ewe e Fon, os quais em geral cultuam divindades chamadas voduns. Algumas particularidades no culto são acionadas pelos grupos para se diferenciar internamente gerando subclassificações como jeje-marrim (mahi), jeje savalu, jeje dagomé, jeje-mundunbi, jeje-mina, jeje-nagô etc.

3 Reconhecido como patrimônio cultural do Brasil pelo Instituto do Patrimônio Histórico e Artístico Nacional (Iphan) em 2014.

4 Terreiro reconhecido como patrimônio pelo Conselho $\mathrm{Mu}$ nicipal de Defesa do Patrimônio Histórico, Artístico, Arquitetônico-Urbanístico e Paisagístico (Comdephaapasa) desde 2008.

5 A Casa das Minas foi tombada pelo Instituto do Patrimônio Histórico e Artístico Nacional (Iphan) em 2002, e a Casa de Nagô pelo Patrimônio Histórico-Arquitetônico e Urbanístico do Estado do Maranhão em I985.

6 Além desses voduns jovens, nos cultos afro-maranhenses em geral a função de mensageiro também pode ser desempenhada por outras entidades caboclas ou encantados, como Surrupira, Legua Boji, Turcos etc. (Ferretti, 2006: 3). 
7 Veja cartas enviadas pelo rei Adandozan a dom João de Portugal, em 1804, nas quais o primeiro manifesta sua devoção "ao grande deus Leba" (Verger, I987: 273, 287; Parés, 2013: $354,355,358)$.

8 Aizan é um vodum feminino associado à terra, fertilidade, fartura, ancestralidade (antepassados) e comunicação. Muitas vezes é descrita como esposa de Legba. No terreiro jeje fundado por pai Dancy em São Paulo, seu assentamento é constituído por dois potes brancos ao lado de cactos. É cultuada também em montículo de terra enfeitado por folhas de dendezeiro.

9 Cerimônia privativa que antecede as festas públicas.

Io Terecô, Tambor da Mata ou Bárbara Soeira denominam tradições religiosas que cultuam entidades caboclas e encantados (encantaria) e têm forte apego à magia curativa e ao feitiço. Atribui-se à cidade de Codó o epíteto de "capital da magia negra do Brasil".

I I Essa hipótese é também afirmada pelo linguista beninense Hyppolyte Brice Sogbosi, para quem Légua Boji pode ser "Legba Gboji", que significa "no portão de Legba" (Ferretti, 2003: 2).

\section{REFERÊNCIAS BIBLIOGRÁFICAS}

Bastide, Roger. (I978). O candomblé da Bahia - rito nagô. São Paulo: Nacional.

Cabrera, Lydia. (2004). Iemanjá \& Oxum. Iniciações, ialorixás e Oolorixás. São Paulo: Edusp.

Castro, Yeda Pessoa de. (2004). De como Legba tornou-se interlocutor dos deuses e dos homens. Caderno Pós de Ciências Sociais. São Luís, I/2.

Centriny, Cícero. (2015). Terecô de Codó. Uma religião a ser descoberta. São Luís: Zona V Fotografias Ltda.

Dopamu, P. Ade. (I990). Exu. O inimigo invisível do homem. São Paulo: Editora Oduduwa.

Ellis, Alfred Burdon. (2007) [1894]. Yoruba-speaking peoples of the slave coast of west Africa: their religion, manners, customs, laws, language. Charleston: Bibliobazaar.

Ellis, Alfred Burdon. (1890). The Ewe-Speking people. London: Chapman and Hall. 
Fernandes, Gonçalves. (I937). Xangôs do Nordeste. Rio de Janeiro: Civilização Brasileira.

Ferretti, Mundicarmo. (2009). Nagô é Nagô! Identidade e resistência em um terreiro de mina de São Luís (MA). Paper apresentado na IV Jornada Internacional de Políticas Públicas, São Luís.

Ferretti, Mundicarmo. (1999). Religião e magia no Terecô de Codó. In: Caroso, Carlos \& Bacelar, Jeferson (orgs.). Faces da tradição afro-brasileira. Rio de Janeiro: Pallas/Ceao/ CNPq.

Ferretti, Mundicarmo. (1993). Desceu na guma: o caboclo do tambor de mina no processo de mudança de um terreiro de São Luís: a Casa de Fanti-Ashanti. São Luís: Sioge.

Ferretti, Sergio. (2006). A terra dos voduns. Disponível em: <http://hdl.handle.net/I/300>. Acesso em I5 jan. 2019. Ferretti, Sergio. (1986). Querebentam de Zomadonu. Etnografia da Casa das Minas. São Luís: Edufma.

Link, Luther. (1998). O Diabo. A máscara sem rosto. São Paulo: Companhia das Letras.

Maupoil, Bernard. (2017). A adivinhação na antiga Costa dos Escravos. Tradução de Carlos Eugênio Marcondes de Moura. São Paulo: Edusp.

Parés, Nicolau. (20I6). O rei, o pai e a morte. A religião vodum na antiga Costa dos Escravos na África Ocidental. São Paulo: Companhia das Letras.

Parés, Nicolau. (2013). Cartas do Daomé. Uma introdução. Afro-Ásia, Salvador, 47, p. 295-395.

Parés, Nicolau. (2006). A formação do candomblé. História e ritual da nação jeje na Bahia. Campinas: Editora Unicamp.

Peixoto, Antonio da Costa. (I943-I944) [I74I]. Obra nova da língua geral de mina. Manuscrito da Biblioteca Pública de Évora, publicado e apresentado por Luis Silveira em 1943. Lisboa: Agência Geral das Colônias.

Valente, Waldemar. (1955). Sincretismo religioso afro-brasileiro. São Paulo: Editora Nacional.

Verger, Pierre Fatumbi. (I999) [1957]. Notas sobre o culto aos orixás e voduns na Bahia de todos os santos, no Brasil, e na antiga Costa dos Escravos, na África. São Paulo: Edusp. 
ARTIGO | VAGNER GONÇALVES DA SILVA

Verger, Pierre. (I990). Uma rainha africana mãe de santo em São Luís. Revista da USP, São Paulo, 6, p. I5I-I58.

Verger, Pierre. (1987). Fluxo e refluxo do tráfico de escravos entre o Golfo do Benin e a Bahia de Todos os Santos. Dos séculos XVII a XIX. São Paulo: Corrupio. 


\section{LEGBA NO BRASIL - TRANSFORMAÇÕES E CONTINUIDADES DE UMA DIVINDADE}

\begin{abstract}
Resumo
Neste artigo apresento as transformações e continuidades do culto no Brasil a Legba, entidade africana de origem fon-ewe, com especial atenção a sua prática no tambor de mina maranhense. Parto do processo de reinterpretação feito pelos europeus dessa entidade na África e como esse processo se estendeu ao Brasil por ocasião da Diáspora Africana ocasionada pela escravidão. Meu argumento central é que esse processo de trocas estendido para as Américas ganhou novos interlocutores e complexidade ainda maior afetando os vários sistemas em contato. Se, por um lado, o trabalho da conversão obrigatória propiciou a demonização de Legba, por outro lado, certas características de Legba possibilitaram uma absorção do catolicismo segundo os princípios cosmológicos da mitologia africana de origem.
\end{abstract}

\section{LEGBA IN BRAZIL - CONTINUITIES AND TRANSFORMATIONS OF A DEITY} and how this process was extended to Brazil during the African Diaspora caused by slavery. My central argument is that the extension of this process of exchanges to the Americas acquired new interlocutors and even greater complexity, affecting the various systems in contact. While, on one hand, the work of compulsory conversion led to the demonization of Legba, on the other, certain characteristics of Legba made possible an absorption of Catholicism in accordance with the cosmological principles of the African mythology of origin.
Palavras-chave

Legba;

demônio;

candomblé jeje;

religiões afro-brasileiras;

divindades.

\section{Keywords}

Legba; demon; candomblé jeje; Afro-Brasilian religions; deities. 